\title{
Sentiment in Oil Markets
}

\section{Peter Deeney, Mark Cummins, Michael Dowling, Adam Bermingham}

peter.deeney2@mail.dcu.ie

mark.cummins@dcu.ie

michael.m.dowling@tcd.ie

adambermingham@gmail.com

Key Words: market sentiment, crude oil, energy, multiple hypothesis testing.

\begin{abstract}
Sentiment is shown to influence both West Texas Intermediate (WTI) and Brent futures prices during the period 2002 - 2013. This is demonstrated while controlling for stock indices, exchange rates, financial costs, inventory and supply levels as well as OPEC activity. Sentiment indices are developed for WTI and Brent crude oils using a suite of financial proxies similar to those used in equity research where the influence of sentiment has already been established. Given the novel nature of this study, multiple hypothesis testing techniques are used to ensure that these conclusions are statistically robust.
\end{abstract}

JEL Classification $\quad$ C12, C22, C52, Q43

This material is based upon works supported by Dublin City University under the Daniel O'Hare Research Scholarship scheme awarded to Peter Deeney. Mark Cummins and Michael Dowling are from the Dublin City University Business School.

Adam Bermingham of The Insight Centre for Data Analytics based in Dublin City University is supported by Science Foundation Ireland under Grant Number SFI/12/RC/2289. 


\section{Introduction}

This research is motivated by evidence that sentiment influences the behaviour of the stock markets. We show that sentiment influences prices in the professionally-traded oil markets by measuring sentiment using indices constructed from a suite of appropriate financial oil market proxies. These indices for West Texas Intermediate (WTI) and Brent crude oils significantly improve a fundamental model of oil prices for each oil during the period January 2002 - December 2013.

Sentiment is not only a phenomenon observed by professional traders but sentiment influences professional traders. O'Connell and Teo [2009] demonstrate trader overconfidence; Coates and Herbert [2008] show a link between testosterone levels and trading outcomes; Froot et al. [2011] show that current trading decisions are subject to sensitivity to past portfolio losses, while a recent qualitative study by Fenton-O'Creevy et al. [2011] of 118 UK-based professional traders in equity, bond, and derivatives markets finds that traders allow emotions to influence their trading decision-making in a manner that deviates from purely rational decision-making.

Sentiment is known to exist in the equity markets. Schmeling [2009] reports that sentiment has a significant influence on stock market returns across many industrialised countries and has a greater effect on countries which have less market integrity and more herd-like behaviour from investors. The work of [Baker and Wurgler, 2006] shows that sentiment is most influential on firms which are difficult to value. This confirmed the work of [Barberis et al., 1998] which shows that decisions made regarding investment are at times biased and subject to systematic errors. These effects are not removed by arbitrage due to the limits to arbitrage encountered in the equity markets as described by Barberis and Thaler [2003].

[Wang, 2001] shows that sentiment is active in the agricultural commodity markets. Borovkova [2011] demonstrates the influence of sentiment in the oil markets by showing that the shape of the forward curve is influenced by very strong or very weak sentiment as measured by the Thomson Reuters NewsScope product. ${ }^{1}$ Dowling et al. [2014] show evidence for the existence of psychological price barriers in the crude oil markets. Borovkova [2011] and Dowling et al. [2014] show that sentiment is influential in the oil market. However, these papers do not consider the whole range of sentiment. We show that sentiment can be quantified and used to explain price movements. In this investigation we use sentiment in oil price models for WTI and Brent and treat it as an additional variable to the chosen fundamental variables. In doing so we add to the literature showing that sentiment does not just have an influence in extreme or in specific circumstances but has a widespread measurable effect.

We propose that there is sentiment in the oil markets because of the need for speculation and because of information asymmetry between oil producers and the other market participants. Long and short hedging activity in the oil markets is not balanced

\footnotetext{
1 Thomson Reuters Newscope measures the sentiment of the text in news reports using a proprietary sentiment engine, the details of which are not publicly available.
} 
[Hirshleifer, 1990]. Oil producers are vulnerable to unexpected changes in the price of oil and need short hedging positions. However, oil consumers are less vulnerable as they have many other cost pools in addition to oil prices and so have a lesser need for long hedging positions. This is in keeping with hedging pressure theory from Keynes [1930] and Hicks [1939]. Thus we have a situation where speculators provide insurance to producers by taking the excess long positions not taken by consumers, but only producers have access to all the information regarding oil reserves and supply issues.

[Kaufmann, 2011], [Coleman, 2012], [Fan and Xu, 2011] and [Cifarelli and Paladino, 2010] all show that speculation is an important driver of oil prices. As with the equity markets there are limits to arbitrage, namely the size of the positions traders are permitted to take and the size of the margin calls which traders will incur while they wait for their profits to materialize. Acharya et al. [2013] make it clear that the limits imposed by margin calls make arbitrage partially ineffective in the oil markets. Therefore arbitrage is limited in its ability to remove the effect of sentiment.

Following the methods applied by Baker and Wurgler [2006], Lemmon and Portniaguina [2006] and Baker et al. [2012] in their analysis of the equity markets, we build a similar oil sentiment index and compare the performance of a fundamental model before and after this sentiment index has been included. Prompt month futures of WTI and Brent crude oils are used from January 2002 to December 2013 at monthly frequency.

Baker and Wurgler [2006] used the following sentiment proxies in an equity context: volume of trades, market volatility, closed end fund discount, IPO number and opening returns, and the put call ratio. None of these was, on their own, a simple measure of sentiment; each had an idiosyncratic component but a principal component analysis (PCA) was applied to extract the common signal. In this investigation we use: the volume of the oil futures traded, the historic volatility of the oil price, the put-call ratio of oil options, the ratio of speculative trades to oil demand and the implied volatility of a local stock market index, namely the S\&P 500 for WTI and the Euro Stoxx 50 for Brent. None of these is a pure measure of sentiment but, we use a PCA process to extract the common signal similar to Baker and Wurgler [2006].

The selected proxies for WTI or Brent crude oil are entered into a principal component analysis, the first principal component of which is defined as the sentiment index for each oil. It is established that low correlations exist between changes in the sentiment indices and changes in a range of key fundamental economic variables, showing that the effectiveness of these indices is not a consequence of fundamental information. As these sentiment indices are extracted from proxies for sentiment similar to proxies used in equities research, it is reasonably argued that these indices are measuring oil market sentiment.

To test the influence of the sentiment indices for WTI and Brent crude oil, each index is added to a benchmark oil price model consisting of non sentiment variables. The effect of sentiment on oil prices is then evaluated statistically while explicitly controlling for key fundamental variables that are known to drive oil prices. These key fundamental drivers are: 
broad economic performance as measured by stock index movements, we use the S\&P 500, Euro Stoxx 50, Hang Seng and Nikkei which represent the US, the Eurozone, China and Japan the world's four largest consumers of oil, following Li and Lin [2011];

1. the US dollar exchange rates for the stock indices used in (i), namely the Euro, Japanese Yen and Hong Kong dollar following Reboredo [2012], Beckmann and Czudaj [2013] and Brahmasrene et al. [2014] who indicate a direct connection between foreign exchange rates and oil prices;

2. the Baltic Dry Index (BDI), following Kilian [2009] and Coleman [2012];

3. the cost of corporate debt, where we use Moody's Aaa as a benchmark corporate bond rate, following Coleman [2012];

4. the US oil inventory and the World oil supply, and

5. OPEC's spare capacity and proportion of world production following Kaufmann [2004], Lin and Tamvakis [2010] and Coleman [2012].

To informally measure the improvement to the fundamental model we calculate the adjusted $\mathrm{R}^{2}$ and F-test results; the likelihood ratio test is used to formally test whether the improvement to the models after the inclusion of the sentiment indices is significant or not. As we perform 92 simultaneous hypothesis tests, it is necessary to address the multiple comparison problem. That is, when many hypothesis tests are being carried out simultaneously there is a probability that some null hypotheses may be rejected falsely. This is addressed with a generalised version of the multiple hypothesis testing procedure of Holm [1979].

The remainder of the paper is set out as follows. Section 2 explains the selection of the proxies and the method by which principal component analyses were used to form the oil sentiment indices for WTI and Brent. Section 3 shows the methods used for building the fuel price benchmark models against which the two indices will be tested. Section 4 presents the empirical results for WTI and Brent crude oils and demonstrates the robustness of our finding that sentiment influences oil prices using a multiple hypothesis testing (MHT) framework. Section 5 concludes.

\section{Creating an oil sentiment index}

In this section the method of constructing an oil sentiment index is described. The construction involves combining proxies for sentiment using PCA, as used by [Baker and Stein, 2004], [Baker and Wurgler, 2006], Lemmon and Portniaguina [2006], and Mian and Sankaraguruswamy [2012] who examine sentiment in the equities market. The proxies used for the oil markets are selected so as to be similar to those which have been used building sentiment indices in equity research. 


\subsection{Selecting the oil sentiment proxies}

Equities research uses a wide variety of proxies for sentiment. None of these proxies are a perfect measure of sentiment but they are combined using principal component analysis (PCA) to produce useful sentiment indices. In the same way proxies for sentiment are chosen from the oil market data and are combined using PCA to form a sentiment index for each of WTI and for Brent crude oils.

Baker and Wurgler [2006] use the following proxies NYSE turnover, closed end fund discount, number of and average first day return of IPOs, share of equity issues in total equity and debt issues and dividend premium. These are combined in the PCA process to produce a sentiment index. Baker and Wurgler [2006] explain that while each proxy will contain an idiosyncratic as well as sentiment component, the PCA isolates the common sentiment component. We chose appropriate oil market proxies based on sentiment research in equities which measure market activity, oil price volatility, market fear, speculation and general stock market volatility. These choices are supported from within the literature as set out below and in Table 1 . The proxies selected to build the oil sentiment indices are specific to each crude oil as follows:

1. the trading volume of the prompt-month futures contract

2. the 30-day historical volatility of the prompt-month futures price

3. the put call ratio for options on oil futures

4. an oil speculation indicator, namely the ratio of non-commercial futures and options positions to oil demand, and

5. a geographically appropriate implied volatility index (VIX for WTI and the volatility of the Euro Stoxx 50 for Brent).

Volume of trades are used as a proxy for investor sentiment by [Scheinkman and Xiong, 2003], [Baker and Stein, 2004], [Baker and Wurgler, 2007] and [Canbaş and Kandır, 2009]. While it is clear that the volume of trades is a direct measure of market activity, the literature shows that it is also an indicator of market sentiment.

Volatility is considered to be a measure of market fear by Whaley [2000], hence the choice of a volatility measure as a sentiment proxy for each oil. The oil-based implied volatility measure (OVX) was not available for the 12 years required. Hence the 30-day historical volatility of the oil futures price is used. This is calculated as the standard deviation of the log price returns for the previous 30 trading days for prompt month futures contracts. Thirty-day volatility, which uses approximately the previous month-and-a-half of price data, was chosen as it is a reasonable compromise between the measurement of the volatility being accurate and being current. The volatility figures are obtained from Bloomberg LP and are the second proxy. 


\begin{tabular}{|c|c|c|c|}
\hline Measure & Equity Proxy & Oil Proxy & References \\
\hline $\begin{array}{l}\text { Market } \\
\text { Activity }\end{array}$ & $\begin{array}{l}\text { Volume of } \\
\text { trades in the } \\
\text { stock market }\end{array}$ & $\begin{array}{l}\text { Volume of } \\
\text { trades of oil } \\
\text { futures }\end{array}$ & $\begin{array}{l}\text { Scheinkman and Xiong } \\
{[2003]} \\
\text { Baker and Stein [2004] } \\
\text { Baker and Wurgler [2006] } \\
\text { Canbaş and Kandır [2009] }\end{array}$ \\
\hline $\begin{array}{l}\text { Asset } \\
\text { Volatility }\end{array}$ & $\begin{array}{l}\text { Volatility of } \\
\text { historic market } \\
\text { return }\end{array}$ & $\begin{array}{l}\text { Volatility of } \\
\text { historic futures } \\
\text { returns }\end{array}$ & Whaley [2000] \\
\hline $\begin{array}{l}\text { Market } \\
\text { Fear }\end{array}$ & $\begin{array}{l}\text { Put call ratio for } \\
\text { equity options }\end{array}$ & $\begin{array}{l}\text { Put call ratio } \\
\text { for oil options }\end{array}$ & Bathia and Bredin [2013] \\
\hline Speculation & $\begin{array}{l}\text { IPO volume and } \\
\text { initial returns }\end{array}$ & $\begin{array}{l}\text { Ratio of non } \\
\text { commercial } \\
\text { trading volume } \\
\text { to oil demand }\end{array}$ & $\begin{array}{l}\text { Coleman [2012] } \\
\text { Bunn and Chen [2013] } \\
\text { Kolodziej and Kaufmann } \\
{[2013]}\end{array}$ \\
\hline $\begin{array}{l}\text { Market } \\
\text { Volatility }\end{array}$ & $\begin{array}{l}\text { An implied } \\
\text { volatility index }\end{array}$ & $\begin{array}{l}\text { An implied } \\
\text { volatility index }\end{array}$ & $\begin{array}{l}\text { Simon and Wiggins III } \\
\text { [2001] } \\
\text { Whaley }[2000,2009]\end{array}$ \\
\hline
\end{tabular}

Tab. 1: Comparison of Proxies for Sentiment in the Equity Markets and the Oil Markets 
The put-call ratio has been used as a measure of market fear in equity research, for example by Bathia and Bredin [2013]. The put-call ratio for oil futures options is the third proxy. The data used is the aggregated open interest futures from Bloomberg LP.

Speculation was measured by Coleman [2012] and Bunn and Chen [2013] using the churn ratio, which was the ratio of the number of forwards or futures contracts to physical delivery, this indicated the level of speculation in the oil and electricity markets respectively. A more specific measure was also used, namely the number of non-commercial futures positions from the CFTC. This measure was used by Kolodziej and Kaufmann [2013]. (The US Commodity Futures Trading Commission (CFTC) defines a commercial position as one held by someone who produces, processes or sells the commodity, this includes using futures to hedge actual exposure to commodity prices.) In this investigation, we combine these two methods and use the ratio of noncommercial WTI futures to world oil supply from the US Dept of Energy as a speculation indicator for WTI. A similar indicator for Brent is constructed from the corresponding data from the CFTC for Brent non-commercial futures positions where available and is the fourth proxy. A difficulty with the data is that Brent non-commercial data is unavailable before April 2008; to overcome this the WTI data is used in its place from January 2002 to March 2008, this is a reasonable approximation as the price of Brent and WTI were very closely aligned before 2011.

The VIX was used as a proxy of sentiment by [Simon and Wiggins III, 2001]. Volatility indices are considered to be measures of investor fear or anxiety [Whaley, 2000, 2009]. The VIX is the weighted average of implied volatilities of first and second month options on the Chicago Board of Trade. We use this measure as a proxy when analysing WTI. The volatility of the Euro Stoxx 50 index (V2X) is used for Brent. The Euro Stoxx 50 index is comprised of 50 of the largest stocks in the Eurozone and represents more than $50 \%$ of all the Eurozone equities by capitalisation. Equity index volatility is the fifth and final proxy and is chosen as a proxy for overall sentiment in the economy.

\subsection{Building a sentiment index by principal component analysis}

This investigation uses PCA to produce a linear combination of the proxies. The first principal component is the linear combination of the proxies which captures the maximum variance compared with other linear combinations subject to normalisation. [Baker and Wurgler, 2007] offer two comments regarding the robustness of this method: first that it reduces reliance on individual proxies (even though measured individually some are very significant); and second, that an index constructed from individual proxies would behave almost identically to that formed by PCA.

A first stage index is constructed (following Baker and Wurgler, 2006) to decide whether to use each proxy's current value or its first time-lagged value. This is to take into consideration the possibility that some of the proxies may be stronger leading indicators than others. The first stage index is the first principal component of all the current and first lags of the proxies. For each proxy the correlation of the current value 
with the first stage index and the correlation of the proxy's first lag with the first stage index are calculated. The larger value decides whether the current or first lag is chosen to build the sentiment indices. The selected proxies are then used in a second PCA stage, the first principal component of which is defined to be the sentiment index for the crude oil in question.

The results of the PCA based oil sentiment construction processes are summarised in Table 2. Thus for WTI and Brent the sentiment indices are calculated as follows,

WTI Sentiment $_{t}=0.36$ Trading Volume $_{t-1}-0.44$ WTI Volatility $_{t}-0.53$ Put Call Ratio V $_{-1}$

$$
+0.59 \text { Spec } W T I_{t}-0.22 \text { VIX } X_{t-1}
$$

BrentSentiment $_{t}=0.19$ Trading Volume $_{t-1}-0.63$ BrentVolatility $_{t}+0.06$ PutCall Ratio P $_{-1}$

$$
0.46 \text { Spec Brent }_{t}-0.60 \text { Volatility of Stox } x_{t-1}
$$

where WTI or Brent Volatility is the 30-day historical volatility of WTI or Brent and Spec WTI or Spec Brent is the speculation indicator for each oil. The PCA process calculates the ratio of the components which maximises variance subject to the sum of the squared loadings being one.

Wang [2001] showed that sentiment from speculators and hedgers did contain useful information regarding the movements of agricultural commodity prices but that sentiment from small traders was not useful. It is conjectured here that sentiment in the professionally-traded oil markets is useful as the vast majority of the traders in the energy markets are highly informed professionals. When Baker and Wurgler [2006], Lemmon and Portniaguina [2006] and Chung et al. [2012] examined the stock markets they used an orthogonalisation procedure to remove from the equity sentiment proxies anything which could be attributed to the economic cycle. This procedure effectively produced an index which depended heavily on the choice of economic cycle variables. In order to capture the sentiment in the oil markets, this orthogonalisation step is not carried out. This choice keeps the sentiment indices and the fundamental variables independent of each other. This approach is argued to be reasonable due to there being insignificant or low correlation between the oil sentiment indices and the fundamental variables (Table 3). This finding also refutes a criticism that the sentiment indices are effective because they capture fundamental information.

\subsection{The sentiment indices for WTI and Brent}

Figure 2.1 plots the WTI and Brent sentiment indices as well as the log of the WTI and Brent price series. It is seen that the Brent sentiment index is quite similar to that 
of WTI with both showing a general upward trend over the period. In addition both have a severe dip during the period of rapid oil price change in 2008.

Table 3 shows that there is low or insignificant correlation between the first differences of the two sentiment indices and the first differences of the key fundamental variables that we will consider in the fundamental oil price models, which will be defined later in Eq.3.1 and Eq.3.2. This demonstrates that the indices are not simply capturing information from these fundamental variables but are also bringing new information to the model. As this information is extracted from proxies modelled on channels of sentiment in equity markets, it is reasonably argued that the oil sentiment indices are measuring oil market sentiment.

\begin{tabular}{lcc|cc}
\cline { 2 - 5 } & \multicolumn{2}{c|}{ WTI } & \multicolumn{2}{c}{ Brent } \\
\cline { 2 - 5 } & $\begin{array}{l}\text { Current (t) } \\
\text { or Lag (t-1) }\end{array}$ & Loading & $\begin{array}{c}\text { Current (t) } \\
\text { or Lag (t-1) }\end{array}$ & Loading \\
\hline Trading Volume & $\mathrm{t}-1$ & 0.36 & $\mathrm{t}-1$ & 0.19 \\
30-Day Volatility & $\mathrm{t}$ & -0.44 & $\mathrm{t}$ & -0.63 \\
Put Call Ratio & $\mathrm{t}-1$ & -0.53 & $\mathrm{t}-1$ & 0.06 \\
Speculation & $\mathrm{t}$ & 0.59 & $\mathrm{t}$ & 0.46 \\
Indicator & & & $\mathrm{t}-1$ & -0.60 \\
VIX / V2X & $\mathrm{t}-1$ & -0.22 & $27 \%$ & \\
Variance & $33 \%$ & & & \\
Explained & & & & \\
\hline
\end{tabular}

The table shows the loadings from the principal component analysis of the WTI and Brent sentiment proxies. The choice of current $(\mathrm{t})$ or first lag ( $\mathrm{t}-1)$ is made using the method of Baker and Wurgler (2006). The linear combination of these proxies with their loadings is the first principal component for each set of sentiment proxies. This first principal component is the sentiment index for each crude oil. The percentage of variance explained by this first component is listed. V2X is the volatility index based on the Euro Stoxx 50.

Tab. 2: PCA loadings for WTI and Brent Oil Sentiment indices.

\section{Testing framework}

To test whether changes in the oil sentiment indices explain price movements in promptmonth futures contracts for WTI and Brent, a benchmark model for these crude oils is proposed and tested using a multivariate regression. The benchmark model is specifically chosen to capture fundamental rather than sentiment influences on oil prices. The oil sentiment indices are added to the benchmark model for each crude oil and the extended models are tested again. Changes in model performance are measured using the informal adjusted $\mathrm{R}^{2}$ measure and variance ratio tests, along with formal likelihood ratio tests. A common model for both oils is used so that a fair comparison may be made of the effect of the sentiment index on WTI and Brent crude oils. 


\begin{tabular}{lcc}
\cline { 2 - 3 } & $\Delta$ WTI Sentiment Index & $\Delta$ Brent Sentiment Index \\
\hline$\triangle$ SP500 & 0.37 & 0.10 \\
$\Delta$ Euro Stoxx & 0.36 & -0.05 \\
$\Delta$ Nikkei & 0.31 & 0.10 \\
$\Delta$ Hang Seng & 0.27 & 0.21 \\
$\Delta$ USDEUR & -0.20 & -0.24 \\
$\Delta$ USDJPY & 0.14 & 0.01 \\
$\Delta$ USDH KD & -0.05 & 0.03 \\
$\Delta$ BDI & -0.01 & 0.14 \\
$\Delta$ Moody & -0.10 & -0.03 \\
$\Delta$ US Oil Inventory & 0.05 & 0.00 \\
$\Delta$ World Oil Supply & -0.06 & -0.09 \\
$\Delta$ OPEC Surplus & 0.14 & 0.13 \\
$\Delta$ OPEC Proportion & -0.18 & 0.09 \\
\hline
\end{tabular}

The table shows the correlations between the first differences of the fundamental variables, and the first differences of the sentiment indices for WTI and Brent crude oils. These fundamental variables are used in the benchmark models of oil price. The results are generally very low correlation with 18 of the 26 correlations below the $5 \%$ significance level of 0.1642 . The sentiment index for WTI is weakly correlated with the stock indices which is expected as the US is a larger oil producer than Europe.

Tab. 3: Correlation Table: Sentiment Indices and Fundamental Benchmark Variables

\subsection{Benchmark model specification}

Benchmark models for WTI and Brent are proposed at monthly frequency using the following fundamental variables:

1. Equity indices: S\&P 500, Euro Stoxx, Nikkei and Hang Seng

2. The US\$ exchange rate for the Euro, the Japanese Yen and the Hong Kong dollar

3. Baltic Dry Index

4. Corporate bond rates, where we specifically consider Moody's Aaa corporate bond rate

5. US oil inventory and World oil supply

6. OPEC's proportion of world production and OPEC's spare capacity.

We choose a selection of equity indices, from the US (world's largest oil consumer), the Eurozone (2nd), China (3rd) and Japan (4th) which together accounted for $50 \%$ of world oil consumption in 2012 (US Energy Information Administration). These regions are represented in our testing by S\&P 500, EuroStoxx 50, Hang Seng and the Nikkei stock indices. There is abundant literature addressing the interactions of oil prices and 


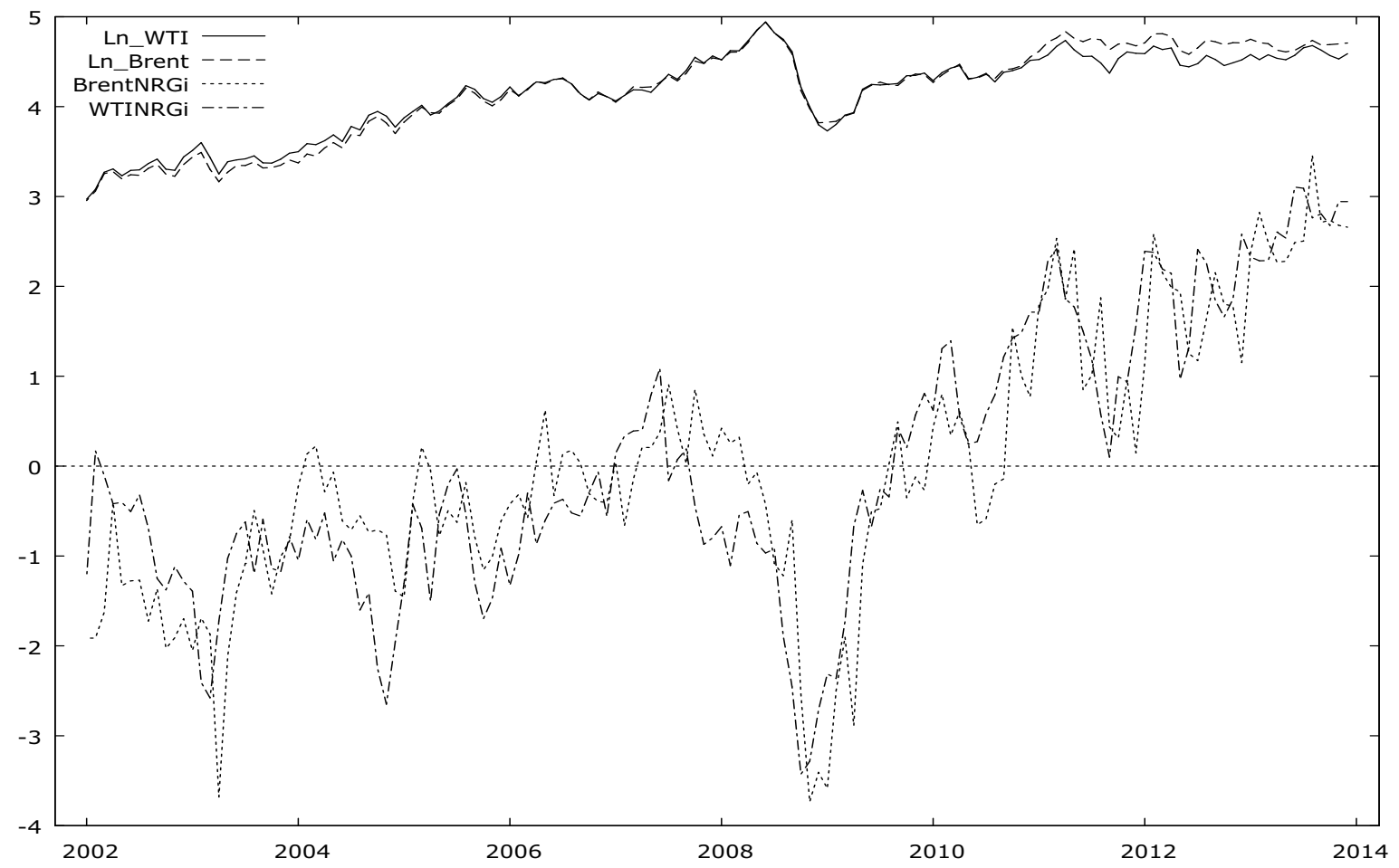

Fig. 2.1: Log of WTI and Brent prices and their Sentiment Indices

stock prices. Jones and Kaul [1996] have reported negative co-movements of stock prices in response to oil price shocks between 1947 and 1991, although Fan and Xu [2011] find that from 2004 to 2009 the S\&P 500 did not provide a significant explanation of oil prices. Zhang and Li [2014] have found close correlations between oil prices and equity indices, with the signs of the correlation always positive, which is also the case here. There has been some debate concerning the influence of Asian demand on oil prices (see Li and Lin 2011, Beirne et al. 2013 and Alquist and Gervais 2013) which supports the inclusion of Hong Kong and Japanese stock indices. It is clear that there is a complex relationship between oil price and equity prices and hence stock markets must be part of the fundamental model. The variables $S \& P 500_{t}$, Stoxx $50_{t}, N K Y_{t}$, Hang Seng are the S\&P 500, Euro Stoxx 50, Nikkei and Hang Seng stock indices.

Beckmann and Czudaj [2013] have found that nominal dollar depreciation causes nominal oil price increase. Brahmasrene et al. [2014] find that US exchange rates Granger cause oil prices in the short run, although Reboredo [2012] finds that oil price and exchange rate interaction is weak. These findings and the selection of stock indices lead to the choice of the US Dollar against the Euro, Yen and Hong Kong dollar as the exchange rates for the benchmark model. The variables $U S D E U R_{t}, U S D J P Y_{t}$ and $U S D H K D_{t}$ are the values of $\$ 1$ US expressed in Euro, Yen or Hong Kong Dollars. 
The Baltic Dry Index which tracks the cost of shipping goods across the oceans is used as an indicator of global industrial production following [Mitchell et al., 2005], [Frale et al., 2008], [Kilian, 2009], Fan and Xu [2011] and [Coleman, 2012] . A criticism of using the BDI is that it is influenced by fuel costs, and so is an endogenous variable. This problem is addressed by [Kilian, 2009] who states that the variation in BDI rates is much larger than the variation in bunker fuel costs, and so the influence of the endogeneity is not important. $B D I_{t}$ is the Baltic Dry index of shipping costs.

Moody's Aaa corporate bond rate is used because Coleman [2012] suggests that since extraction of oil is a capital-intensive business, the cost of capital should be reflected in the price of oil, and that since oil companies are highly rated Coleman [2012] uses

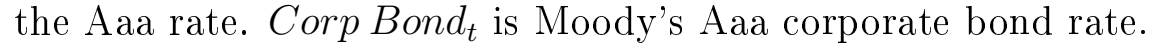

Following the basic law of supply and demand, the US oil inventory and world oil supply from the US Dept of Energy (DOE) are also included. US Oil Inventory $y_{t}$ is the US oil inventory, World Oil Supply $t_{t}$ is the world oil supply.

The proportion of world oil that is produced by OPEC has been found to influence oil prices by Kaufmann [2004], Lin and Tamvakis [2010] and Coleman [2012]. This would occur due to market power. Also included is the difference between OPEC's estimated capacity and the production as this represents the decision of OPEC producers to

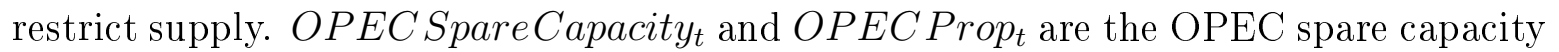
and OPEC proportion of world production.

Based on the above arguments, the benchmark model for WTI and Brent crude oil are set out in Eq. 3.1. Before running the regressions, all the data are log transformed, first-differenced, standardised and checked for stationarity using Augmented Dickey Fuller (ADF) tests which show the log returns of the fundamental variables and sentiment indices to be stationary. Descriptive statistics are given in Table 4 . The benchmark model is given in Eq. 3.1:

$$
\begin{aligned}
& \text { Oil }_{t}=\alpha+\beta_{1} \text { S\&P } 500_{t}+\beta_{2} \text { Stoxx } 50_{t}+\beta_{3} N K Y_{t}+\beta_{4} \text { Hang Seng }, \\
& +\beta_{5} U S D E U R_{t}+\beta_{6} U S D J P Y_{t}+\beta_{7} U S D H K D_{t}++\beta_{8} B D I_{t} \\
& +\beta_{9} \text { Corp Bond }_{t}+\beta_{10} \text { US Oil Inventory } y_{t}+\beta_{11} \text { World Oil Supply } \\
& +\beta_{12} \text { OPEC Spare Capacity } t+\beta_{13} \text { OPEC Prop } \text { P }_{t}+\varepsilon_{t}
\end{aligned}
$$

where all variables are expressed in log returns and $O i l_{t}$ is the WTI or Brent prompt month crude oil price.

With the addition of the sentiment index this model becomes:

$$
O i l_{t}=\alpha+\beta_{1} S \& P 500_{t}+\beta_{2} \text { Stoxx } 50_{t}+\beta_{3} N K Y_{t}+\beta_{4} \text { Hang Seng }
$$




\begin{tabular}{rcccc}
\cline { 2 - 5 } & Mean & Std Dev & Skew & Ex Kurt \\
\cline { 2 - 5 } WTI & 0.011 & 0.091 & -0.797 & 2.030 \\
Brent & 0.012 & 0.086 & -0.939 & 3.148 \\
S\&P 500 & 0.003 & 0.045 & -0.941 & 1.947 \\
Stoxx 50 & -0.001 & 0.057 & -0.764 & 1.301 \\
Nikkei & 0.003 & 0.058 & -0.910 & 2.514 \\
Hang Seng & 0.005 & 0.062 & -0.781 & 2.066 \\
USD Euro & -0.003 & 0.031 & 0.437 & 1.308 \\
USD Yen & -0.002 & 0.027 & 0.338 & 0.369 \\
BDI & 0.006 & 0.249 & -1.453 & 5.614 \\
Bond Rate & -0.002 & 0.037 & -0.726 & 4.909 \\
USD Hong Kong Dollar & 0.000 & 0.001 & -0.220 & -0.122 \\
US Oil Inventory & 0.001 & 0.030 & -0.084 & 1.258 \\
World Oil Supply & 0.001 & 0.007 & -1.668 & 12.383 \\
OPEC Spare Capacity & -0.008 & 0.170 & -0.337 & 2.640 \\
OPEC Proportion & 0.000 & 0.013 & & \\
\hline
\end{tabular}

The table shows descriptive statistics for log returns data used in the benchmark models. The data is from January 2002 to December 2013 ( $\mathrm{N}=144$ months). The price of the prompt month WTI and Brent crude oil futures contracts are in US\$ per barrel. Corporate Bond rate is Moody's Aaa rate. 'Std Dev' is standard deviation, 'Skew' is skewness and 'Ex Kurt' is excess kurtosis.

Tab. 4: Descriptive Statistics 


$$
\begin{gathered}
+\beta_{5} U S D E U R_{t}+\beta_{6} U S D J P Y_{t}+\beta_{7} U S D H K D_{t}++\beta_{8} \text { BDI }_{t} \\
+\beta_{9} \text { Corp Bond }_{t}+\beta_{10} \text { US Oil Inventory } t+\beta_{11} \text { World Oil Supply }_{t} \\
+\beta_{12} \text { OPEC Spare Capacity } \text { SP }_{t}+\beta_{13} \text { OPEC Prop } t+\beta_{14} \text { Oil Sentiment }_{t}+\varepsilon_{t}
\end{gathered}
$$

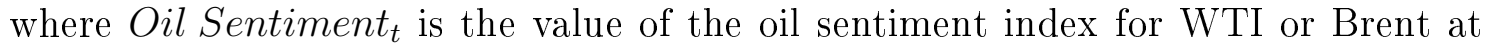
time $t$ measured in months. As is usual practice, standardised variables are used so that comparisons between the variables may be made and so that calculations may not be liable to floating point errors [Aboura and Chevallier, 2013], thus the $\alpha$ terms are zero.

\section{Results}

There is a clear improvement to the benchmark models for WTI and Brent on the inclusion of the oil sentiment indices as is seen in Table 5. This indicates that these indices, and hence oil market sentiment, has a significant influence on WTI and Brent oil prices.

\subsection{Performance of oil sentiment index}

The sentiment indices for WTI and Brent make a statistically significant and economically important improvement to the fundamental models for oil price changes during the 12 years from January 2002 to December 2013. The results are presented in Table 5 and show that the adjusted $\mathrm{R}^{2}$ increases in the WTI and Brent benchmark models from $35 \%$ and $30 \%$ to $52 \%$ and $49 \%$ respectively; in addition the variance ratio test is much more significant. More formally, there is a strongly significant result from the likelihood ratio test of the improvement to the fundamental model, after the inclusion of the sentiment indices for WTI and Brent.

Looking at the results in Table 5 it is notable that the coefficients of the $\mathrm{S} \& \mathrm{P}$ 500, Euro Stoxx 50 and the Nikkei are all insignificant except for Stoxx for WTI when sentiment is included; this anomaly will be revisited below in section 4.2. This is unconvincing evidence that these stock markets have an influence on oil prices. This result is in line with the finding of Fan and Xu [2011] that the S\&P500 was not significant for roughly the same period of time. Following the results of Alquist and Gervais [2013] and Beirne et al. [2013], we find that there is evidence at conventional levels that the Hang Seng significantly explains WTI and Brent prices, but this will be revisited in section 4.2 .

The exchange rates used are expressed as the price of US\$1 in various local currencies, namely the Euro, Yen and Hong Kong dollar. Only the Euro and the Japanese 
Yen are found to be significant, though the Yen is much less significant than the Euro. The cost of one US dollar in Japanese Yen has a positive coefficient meaning that a weakening Yen is on average accompanied by higher oil prices measured in US dollars. The links between exchange rates and oil prices are not entirely straightforward, (see Beckmann and Czudaj 2013, and Reboredo 2012), but it is clear that an appreciation in oil price is accompanied by appreciation of the currency of the exporter, and since Japan produces a much smaller amount of oil than the US (140,000 barrels per day from Japan in contrast to $11,110,000$ from the US $)^{2}$, the positive coefficient is in line with expectations. The coefficient of the cost of US\$1 in Euro is negative, indicating that a weakening Euro against the US dollar is, on average, accompanied by negative oil price returns and so a fall in the price of oil measured in US dollars. This indicates that as the Euro weakens Europeans will actually have to buy fewer of the more expensive dollars to pay for oil. This may be because a depreciation of the local currency causes lower demand for oil, as explained in the 'denomination channel' by Beckmann and Czudaj [2013]. The greater size of Eurozone relative to Japan and the fact that the Eurozone (which does not include UK or Norway) produces 500,000 barrels of oil per day, may explain why the Euro exchange rate coefficient is negative while the Yen's coefficient is positive.

It is interesting that there is very weak evidence that the Baltic Dry Index (BDI) is associated with oil price changes; it is only just significant at the $10 \%$ level. This is unexpected as the BDI has been used as a proxy for worldwide industrial activity by [Mitchell et al., 2005], [Frale et al., 2008], [Kilian, 2009], Fan and Xu [2011], and [Coleman, 2012]. The cost of borrowing as measured by Moody's Aaa corporate bond rate has the expected positive coefficient as found by Coleman [2012] indicating that as borrowing becomes more expensive so does oil. As would be expected by the law of supply and demand, the US oil inventory has a highly significant negative coefficient for WTI prices and a less significant negative coefficient for Brent prices. There is no evidence that world oil supply is significant; which is unexpected. OPEC spare capacity is a measure of the difference between OPEC capacity to deliver oil and the actual quantity delivered, it is thus a measure of how much oil OPEC is holding back from the market. This variable has a positive coefficient as expected. Finally the proportion of world oil production which is from OPEC has a significant positive coefficient indicating that OPEC has considerable market power as is expected from the work of Kaufmann [2004] and Lin and Tamvakis [2010].

\footnotetext{
${ }^{2}$ The 2012 data is from the US Energy Information Administration and was accessed on 29th October 2014 from http://www.eia.gov/countries/
} 


\begin{tabular}{|c|c|c|c|c|}
\hline \multirow{2}{*}{$\begin{array}{r}\text { Jan } 2002 \text { - Dec } 2013 \\
\mathrm{~N}=143 \text { Months } \\
\end{array}$} & \multicolumn{2}{|c|}{$\Delta W T I$} & \multicolumn{2}{|c|}{$\Delta$ Brent } \\
\hline & Bench & Bench + Sentiment & Bench & Bench + Sentiment \\
\hline \multirow[t]{2}{*}{$\Delta S \& P 500$} & 0.110 & 0.215 & 0.086 & 0.098 \\
\hline & $(0.51)$ & $(0.14)$ & $(0.62)$ & $(0.52)$ \\
\hline \multirow[t]{2}{*}{$\Delta$ Stoxx 50} & -0.249 & $-0.340 * *$ & -0.215 & -0.186 \\
\hline & $(0.11)$ & $(0.012)$ & $(0.18)$ & $(0.18)$ \\
\hline \multirow[t]{2}{*}{$\Delta N K Y$} & 0.049 & -0.076 & 0.060 & -0.041 \\
\hline & $(0.65)$ & $(0.41)$ & $(0.59)$ & $(0.67)$ \\
\hline \multirow[t]{2}{*}{$\Delta$ Hang Seng } & $0.247^{* *}$ & $0.232^{* *}$ & $0.247^{* *}$ & $0.225^{* *}$ \\
\hline & $(0.030)$ & $(0.018)$ & $(0.037)$ & $(0.028)$ \\
\hline \multirow[t]{2}{*}{$\triangle U S D E U R$} & $-0.353 * * *$ & $-0.309 * * *$ & $-0.339 * * *$ & $-0.275 * * *$ \\
\hline & $\left(1.4 \times 10^{-4}\right)$ & $\left(1.1 \times 10^{-4}\right)$ & $\left(4.2 \times 10^{-4}\right)$ & $\left(9.3 \times 10^{-4}\right)$ \\
\hline \multirow[t]{2}{*}{$\triangle U S D J P Y$} & $0.197^{* *}$ & $0.213^{* * *}$ & $0.152^{*}$ & 0.112 \\
\hline & $(0.023)$ & $(0.004)$ & $(0.090)$ & $(0.15)$ \\
\hline \multirow[t]{2}{*}{$\triangle U S D H K D$} & 0.074 & 0.010 & 0.118 & 0.042 \\
\hline & $(0.32)$ & $(0.88)$ & $(0.13)$ & $(0.53)$ \\
\hline \multirow[t]{2}{*}{$\Delta B D I$} & 0.107 & 0.078 & 0.110 & $0.113^{*}$ \\
\hline & $(0.16)$ & $(0.23)$ & $(0.16)$ & $(0.097)$ \\
\hline \multirow[t]{2}{*}{$\triangle M o o d y C A A A$} & $0.213^{* * *}$ & $0.125^{* *}$ & $0.173^{* *}$ & $0.154^{* *}$ \\
\hline & $(0.0034)$ & $(0.049)$ & $(0.022)$ & $(0.018)$ \\
\hline \multirow[t]{2}{*}{$\Delta U S$ Oil Inventory } & $-0.186^{* *}$ & $-0.164 * * *$ & $-0.137^{*}$ & $-0.084^{* *}$ \\
\hline & $(0.011)$ & $(0.0096)$ & $(0.073)$ & $(0.020)$ \\
\hline \multirow[t]{2}{*}{$\Delta$ World Oil Supply } & 0.085 & 0.066 & 0.046 & -0.014 \\
\hline & $(0.27)$ & $(0.32)$ & $(0.57)$ & $(0.84)$ \\
\hline \multirow[t]{2}{*}{$\triangle O P E C$ Spare Capacity } & $0.219 * * *$ & $0.118^{*}$ & $0.203^{* *}$ & 0.069 \\
\hline & $(0.0076)$ & $(0.10)$ & $(0.017)$ & $(0.36)$ \\
\hline \multirow[t]{2}{*}{$\triangle O P E C$ Proportion } & $0.167^{* *}$ & $0.143^{* *}$ & $0.165^{* *}$ & $0.175^{* *}$ \\
\hline & $(0.030)$ & $(0.030)$ & $(0.039)$ & $(0.011)$ \\
\hline \multirow[t]{2}{*}{$\Delta$ Oil Sentiment } & & $0.443 * * *$ & & $0.459 * * *$ \\
\hline & & $\left(4.5 \times 10^{-10}\right)$ & & $\left(4.3 \times 10^{-10}\right)$ \\
\hline \multirow{3}{*}{$\begin{array}{r}\text { Log Likelihood } \\
\text { p-value of the Likelihood } \\
\text { Ratio Test }\end{array}$} & 164.43 & 142.64 & 170.36 & 148.50 \\
\hline & & $4.1 \times 10^{-11}$ & & $3.8 \times 10^{-11}$ \\
\hline & & & & \\
\hline \multirow{2}{*}{$\begin{array}{r}\text { Variance Ratio }(\mathrm{F}) \text { Test } \\
\text { Adjusted } \mathrm{R}^{2}\end{array}$} & $4.6 \times 10^{-10}$ & $2.7 \times 10^{-17}$ & $4.9 \times 10^{-8}$ & $3.5 \times 10^{-15}$ \\
\hline & $35.3 \%$ & $51.9 \%$ & $29.7 \%$ & $47.8 \%$ \\
\hline
\end{tabular}

The table shows OLS regression results for the WTI and Brent benchmark models before and after the inclusion of the sentiment index described by Eqns. (3.1) and (3.2). The data has been first differenced and standardized. The likelihood ratio test formally compares model performance of the sentiment model (Bench + Sentiment) relative to the benchmark (Bench) model. *, ${ }^{*}$ and $* * *$ indicate significance at the $10 \%, 5 \%$ and $1 \%$ levels; p-values appear in brackets below each coefficient. Bold print indicates coefficients which were significant under the Generalised Holm Multiple Hypothesis Testing framework.

Tab. 5: OLS Regression Results for WTI and Brent 2002 - 2013 


\subsection{Review of results and discussion}

Recognizing the novel nature of our research into oil market sentiment, we deliberately take a prudent approach. There is a multiple comparisons problem that exists in this testing framework; it is a source of bias that we explicitly address by applying recently developed generalised multiple hypothesis testing (MHT) techniques. The multiple comparisons problem occurs when a large number of hypothesis tests are performed simultaneously, leading to a non-negligible likelihood that some statistically significant results may be identified by pure random chance alone, rather than as a result of any underlying statistical relationships. In our testing framework, the model specifications set out a total of 92 individual hypothesis tests comprising of individual coefficient tests, F tests, the unreported ADF tests and likelihood ratio tests. Hence, the multiple comparisons problem is an important issue to consider and address in order to build robust conclusions. For a more technical treatment of MHT issues, see Holm [1979], Romano et al. [2010], Cummins [2013b] and Cummins [2013a].

To give the greatest power to identify true discoveries, we set a probability of $\alpha=0.1$ as the upper bound probability that there are $k=5$ or more false rejections of null hypotheses amongst the 92 tests; we choose 5 as this is approximately $5 \%$ of the total number of hypotheses tested. Using these criteria we can be much more assured that the conclusions we draw are statistically reliable and robust. In this particular study, the generalised Holm procedure [Romano et al., 2010] leads us to reject 48 null hypotheses while at the conventional significance of $5 \%, 63$ hypotheses would have been rejected. This MHT framework is more conservative than conventional significance levels, where in the latter case one ignores the multiple comparisons problem. In so doing wrong economic conclusions could be drawn from the extra 15 rejected null hypotheses. With this motivation in place, we revisit the results set out in the previous section (4.1) and seek to address the multiple comparisons problem that was not explicitly considered. This is an important statistical correction missing from prior sentiment investigations.

In Table 5 results which are considered significant under the MHT process are indicated in bold. Most notably, there is no change to the conclusion that the sentiment indices for WTI and Brent oil significantly account for oil prices. This is an important finding and allows us to argue with statistical confidence that sentiment affects professionally traded oil markets. It is also found that the US\$ Euro exchange rate significantly explains the movement of oil prices. At the more demanding levels of significance required by the MHT procedure, the anomalous result found perviously that changes in the Stoxx 50 explained WTI price movements is not found to be significant. Furthermore the Hang Seng and the BDI are not found to be significant. The US\$ Yen exchange rate, the Moody corporate bond rate, the US oil inventory, OPEC spare capacity and OPEC proportion are found to be significant. 


\section{Conclusion}

We find that sentiment is an important consideration when explaining WTI and Brent prices using data from Jan 2002 to Dec 2013. This was done following the methods of Baker and Wurgler [2006] by building sentiment indices for both WTI and Brent using similar proxies to those used in equities research. The two indices were constructed using principal component analysis of the following sentiment proxies: volume of futures contracts, the volatility of the oil price, oil speculation indicators, the put-call ratio for options on oil futures and stock index volatility. The inclusion of these sentiment indices significantly improved the performance of fundamental models for oil prices as measured by the likelihood ratio test and also brought about a large increase in the adjusted $\mathrm{R}^{2}$ statistic. The findings are supported by a multiple hypothesis testing framework which gives a very high degree of confidence that we are not merely observing a chance result due to the multiple comparison problem.

Sentiment has already been seen to affect equity markets, our findings expand sentiment to energy markets. This not only leaves open the possibility that sentiment indices can be constructed for energy markets other than oil (gas and coal being the natural next steps), but also acts as a call for further research on the mechanism by which sentiment influences oil pricing, and also a decomposition of this sentiment influence into its rational and irrational components. This latter investigation would be of particular benefit to policy makers seeking to control irrational exuberance and excessive speculation with its associated impact on the economy

\section{Acknowledgments}

The authors would like to acknowledge the helpful comments received at the Euro Working Group on Commodities and Financial Modelling conference in London, England in May 2013, the Irish Accounting and Finance Association conference in Dublin, Ireland in May 2013, the Infiniti conference in Aix-en-Provence, France in June 2013 and the Irish Society of New Economists conference in Maynooth, Ireland in September 2013. In addition comments from Ciara Morley, Brian O'Kelly, Nikos Papapostolou, and Aleksandar Sevic were very useful. The usual disclaimer applies.

\section{References}

S. Aboura and J. Chevallier. Leverage vs. feedback: Which effect drives the oil market? Finance Research Letters, 10(3):131 - 141, 2013. ISSN 1544-6123. doi: http://dx.doi.org/10.1016/j.frl.2013.05.003.

V.V. Acharya, L.A. Lochstoer, and T. Ramadorai. Limits to arbitrage and hedging: Evidence from commodity markets. Journal of Financial Economics, 109(2):441 465, 2013. ISSN 0304-405X. doi: http://dx.doi.org/10.1016/j.jfineco.2013.03.003. 
R. Alquist and O. Gervais. The role of financial speculation in driving the price of crude oil. Energy Journal, 34(3):35 - 54, 2013. ISSN 01956574.

M. Baker and J.C. Stein. Market liquidity as a sentiment indicator. Journal of Financial Markets, 7(3):271-299, 2004.

M. Baker and J. Wurgler. Investor sentiment and the cross section of stock returns. The Journal of Finance, 61:1645 - 1680, 2006.

M. Baker and J. Wurgler. Investor sentiment in the stock market. The Journal of Economic Perspectives, 21(2):129-151, 2007. ISSN 08953309.

M. Baker, J. Wurgler, and Y. Yuan. Global, local, and contagious investor sentiment. Journal of Financial Economics, 104(2):272 - 287, 2012. ISSN 0304-405X. doi: 10.1016/j.jfineco.2011.11.002.

N. Barberis and R. Thaler. A survey of behavioral finance. Abindgon:Routlidge, 2003.

N. Barberis, A. Shleifer, and R. Vishny. A model of investor sentiment. Journal of Financial Economics, 49(3):307 - 343, 1998. ISSN 0304-405X. doi: http://dx.doi.org/10.1016/S0304-405X(98)00027-0.

D. Bathia and D. Bredin. An examination of investor sentiment effect on g7 stock market returns. The European Journal of Finance, 19(9):909-937, 2013. doi: 10.1080/1351847X.2011.636834.

J. Beckmann and R. Czudaj. Is there a homogeneous causality pattern between oil prices and currencies of oil importers and exporters? Energy Economics, 40:665678, 2013. ISSN 0140-9883. doi: http://dx.doi.org/10.1016/j.eneco.2013.08.007.

J. Beirne, C. Beulen, G. Liu, and A. Mirzaei. Global oil prices and the impact of china. China Economic Review, 27(0):37 - 51, 2013. ISSN 1043-951X. doi: http://dx.doi.org/10.1016/j.chieco.2013.07.001.

S. Borovkova. News analytics for energy futures. Available at SSRN 1719582, 2011. doi: http://dx.doi.org/10.2139/ssrn.1719582.

T. Brahmasrene, J. Huang, and Y. Sissoko. Crude oil prices and exchange rates: Causality, variance decomposition and impulse response. Energy Economics, 44:407 - 412, 2014. ISSN 0140-9883.

D.W. Bunn and D. Chen. The forward premium in electricity futures. Journal of Empirical Finance, 23:173 - 186, 2013. ISSN 0927-5398. doi: http://dx.doi.org/10.1016/j.jempfin.2013.06.002.

S. Canbaş and S.Y. Kandır. Investor sentiment and stock return evidence from turkey. Emerging Markets Finance and Trade, 45(4):36-52, 2009. 
San-Lin Chung, Chi-Hsiou Hung, and Chung-Ying Yeh. When does investor sentiment predict stock returns? Journal of Empirical Finance, 19(2):217 - 240, 2012. ISSN 0927-5398. doi: http://dx.doi.org/10.1016/j.jempfin.2012.01.002.

G. Cifarelli and G. Paladino. Oil price dynamics and speculation: A multivariate financial approach. Energy Economics, 32(2):363 - 372, 2010. ISSN 0140-9883. doi: 10.1016/j.eneco.2009.08.014.

J. M. Coates and J. Herbert. Endogenous steroids and financial risk taking on a london trading floor. Proceedings of the National Academy of Sciences of the United States of America, 105(16):6167-6172, 2008. ISSN 00278424.

L. Coleman. Explaining crude oil prices using fundamental measures. Energy Policy, 10:318-324, 2012.

M. Cummins. Multiple comparisons problem: Recent advances applied to energy and emissions. Applied Economics Letters, (20):903-909, 2013a. doi: 10.1080/13504851.2012.761334.

M. Cummins. Eu ets market interactions: The case for multiple hypothesis testing approaches. Applied Energy, 111(0):701 - 709, 2013b. ISSN 0306-2619. doi: http://dx.doi.org/10.1016/j.apenergy.2013.05.032.

M. Dowling, M. Cummins, and B.M. Lucey. Psychological barriers in oil futures markets. Energy Economics, page in press, 2014. ISSN 0140-9883. doi: http://dx.doi.org/10.1016/j.eneco.2014.03.022.

Y. Fan and J.H. Xu. What has driven oil prices since 2000? a structural change perspective. Energy Economics, 33(6):1082 - 1094, 2011. ISSN 0140-9883. doi: http://dx.doi.org/10.1016/j.eneco.2011.05.017.

M. Fenton-O'Creevy, E. Soane, N. Nicholson, and P. Willman. Thinking, feeling and deciding: The influence of emotions on the decision making and performance of traders. Journal of Organizational Behavior, 32(8):1044 - 1061, 2011. ISSN 08943796.

C. Frale, M. Marcellino, G.L. Mazzi, and T. Proietti. A monthly indicator of the euro area gdp. European University Institute Working Papers, 2008/32, 2008.

K. Froot, J. Arabakjis, S. Cates, and S. Lawrence. Evidence on dynamic loss aversion from currency portfolios. Journal of Portfolio Management, 38(1):60 - 68, 2011. ISSN 00954918.

J. Hicks. Value and Capital. Oxford Unversity Press, 1939.

D. Hirshleifer. Hedging pressure and futures price movements in a general equilibrium model. Econometrica, 58(2):411-428, 1990. ISSN 00129682. 
S. Holm. A simple sequentially rejective multiple test procedure. Scandinavian Journal of Statistics, 6(2):65-70, 1979.

C.M. Jones and G. Kaul. Oil and the stock markets. Journal of Finance, 51(2):463 491, 1996. ISSN 00221082.

R.K. Kaufmann. Does opec matter? an econometric analysis of oil prices. Energy Journal, 25(4):67 - 90, 2004. ISSN 01956574.

R.K. Kaufmann. The role of market fundamentals and speculation in recent price changes for crude oil. Energy Policy, 39(1):105 - 115, 2011. ISSN 0301-4215. doi: http://dx.doi.org/10.1016/j.enpol.2010.09.018.

J. Keynes. Treatise on Money. Macmillan London, 1930.

L. Kilian. Not all oil price shocks are alike: Disentangling demand and supply shocks in the crude oil market. The American Economic Review, 99(3):1053-1069, 2009. ISSN 00028282.

M. Kolodziej and R.K. Kaufmann. The role of trader positions in spot and futures prices for wti. Energy Economics, 40:176 - 182, 2013. ISSN 0140-9883. doi: http://dx.doi.org/10.1016/j.eneco.2013.06.002.

M. Lemmon and E. Portniaguina. Consumer confidence and asset prices: Some empirical evidence. The Review of Financial Studies, 19(4):1499-1529, 2006. ISSN 08939454.

H. Li and S.X. Lin. Do emerging markets matter in the world oil pricing system? evidence of imported crude by china and india. Energy Policy, 39(8):4624 - 4630, 2011. ISSN 0301-4215. doi: http://dx.doi.org/10.1016/j.enpol.2011.05.003.

S.X. Lin and M. Tamvakis. Opec announcements and their effects on crude oil prices. Energy Policy, 38(2):1010 - 1016, 2010. ISSN 0301-4215. doi: http://dx.doi.org/10.1016/j.enpol.2009.10.053.

G.M. Mian and S. Sankaraguruswamy. Investor sentiment and stock market response to earnings news. Accounting Review, 87(4):1357 - 1384, 2012. ISSN 00014826.

J. Mitchell, R.J. Smith, M.R. Weale, S. Wright, and E.L. Salazar. An indicator of monthly gdp and an early estimate of quarterly gdp growth. The Economic Journal, 115(501):F108-F129, 2005.

P.G.J. O'Connell and M. Teo. Institutional investors, past performance, and dynamic loss aversion. Journal of Financial and Quantitative Analysis, 44:155-188, 22009. ISSN 1756-6916. 
J.C. Reboredo. Modelling oil price and exchange rate co-movements. Journal of Policy Modeling, 34(3):419 - 440, 2012. ISSN 0161-8938. doi: http://dx.doi.org/10.1016/j.jpolmod.2011.10.005.

J.P. Romano, A.M. Shaikh, and M. Wolf. Hypothesis testing in econometrics. Annual Review of Economics, 2(1):75-104, 2010.

J.A. Scheinkman and W. Xiong. Overconfidence and speculative bubbles. Journal of Political Economy, 111(6):1183 - 1220, 2003. ISSN 00223808.

M. Schmeling. Investor sentiment and stock returns: Some international evidence. Journal of Empirical Finance, 16(3):394-408, June 2009. ISSN 09275398. doi: 10.1016/j.jempfin.2009.01.002.

D.P. Simon and R.A. Wiggins III. S\&p futures returns and contrary sentiment indicators. Journal of Futures Markets, 21(5):447-462, 2001.

C. Wang. Investor sentiment and return predictability in agricultural futures markets. Journal of Futures Markets, 21(10):929-952, 2001.

R. E. Whaley. The investor fear gauge. Journal of Portfolio Management, 26(3):12 17, 2000. ISSN 00954918.

R. E. Whaley. Understanding the vix. Journal of Portfolio Management, 35(3):98 105, 2009. ISSN 00954918.

B. Zhang and X Li. Recent hikes in oil-equity market correlations: Transitory or permanent? Energy Economics, page in press, 2014. ISSN 0140-9883. 